\title{
SWOT Analysis of The Department of General Surgery in A Government Medical College in Kerala
}

\author{
Dr. Habeeb Mohamed ${ }^{1,}$ Dr. Renny Issac ${ }^{2}$,Dr. A. Amar Jayanthi ${ }^{3,}$ \\ Dr. Raseena. $\mathrm{V} \mathrm{K}^{4}$ \\ ${ }^{1}$ Assistant Professor of General Surgery, Government Medical College, Thrissur, Kerala, India \\ ${ }^{2}$ Assistant Professor of General Medicine, Government Medical College, Thrissur, Kerala, India \\ ${ }^{3}$ Professor of Anatomy, Government Medical College, Idukki, Kerala, India \\ ${ }^{4}$ Intern, Government Medical College, Thrissur, Kerala, India
}

\begin{abstract}
A SWOT analysis helps to bring forth the strengths and minimize the weaknesses of the department. The increasing demand for medical profession to deliver high quality health care services in the state and the stagnating level of performance of the MBBS Students prompted the need for SWOT analysis of the Department of General Surgery of a prestigious institution in Kerala, the Government Medical College Kozhikode.The Department of General Surgery is a small department with 31 doctors and 2 auxiliary staff. From this study we found out various problems and solutions to improve their performance through training and non-training interventions. There is a need for the Government to introduce creative incentives like career advancement promotion, higher training, cash incentives for research and flexible working environment.
\end{abstract}

Keywords: SWOT, health care, medical education, faculty training, students perception, surgery department.

\section{Introduction}

SWOT analysis is the analysis of the current status of an institution or department. The SWOT analysis helps to bring forth the strengths and minimize the weaknesses of the department. The increasing demand for medical profession to deliver high quality health care services and the stagnating level of performance of the MBBS students prompted the need for SWOT analysis of the Department of General Surgery of a prestigious institution in Kerala, the Government Medical College Kozhikode. The Government Medical College Kozhikode was founded in 1952 with the aim of promotion of Health Care and Medical Education in the Northern part of Kerala State. The Department of General Surgery is one of the 18 Departments that function in the Government Medical College Kozhikode. The Key Functions of The Department of General Surgery are: Care of the Surgical Patient providing Emergency, Outpatient and Inpatient Care, Conduct of Emergency and Elective Surgeries, Training of Undergraduate and Postgraduate Medical, Dental and Nursing Students, Research in the field of General Surgery and Administration of The Department. The general policies regarding the patient care and health care delivery is decided by the Government of Kerala. The Academic curriculum and the Qualifications of the Staff are decided by the Indian Medical Council. These two institutions govern the functioning of the Medical Colleges of the State. The Department of General Surgery is hence guided by the directions of the said two institutions. The objective of this study is to identify according to a defined set of criteria, the Strength, Weakness, Opportunities and threats of the Department of General Surgery, Government Medical College Kozhikode.

\section{Materials And Methods}

A cross sectional study was conducted in the Department of General Surgery of the Government Medical College Kozhikode from April 2009 to March 2011. Quantitative data regarding the Clinical and Academic activities of the Department was collected from the Annual Administrative Reports of the said two years. Qualitative data was collected by interview with the Head of the Department, Unit Chief, Associate Professor and Assistant Professor of the Department. One faculty from each category was selected at random. The confidentiality of the data was assured to the participants.

\section{Results}

The Department of General Surgery is headed by the Head of the Department who is the senior most Professor. There are three more Professors followed by Associate Professors, Assistant Professors and Lecturers. The Postgraduate Residents and House Surgeons complete the team. The work of the Department is carried out through Units. 


\begin{tabular}{|c|l|c|}
\multicolumn{3}{|c|}{ Teaching Staff } \\
\hline S1. No & Posts & Number Sanctioned \\
\hline 1 & Professor & 4 \\
\hline 2 & Associate Professor & 5 \\
\hline 3 & Assistant Professor & 10 \\
\hline 4 & Lecturer / Senior Residents & 12 \\
\hline
\end{tabular}

\begin{tabular}{|c|l|c|}
\multicolumn{3}{|c|}{ Non Teaching Staff } \\
\hline Sl. No & Posts & Number Sanctioned \\
\hline 1 & Confidential Assistant & 1 \\
\hline 2 & Junior Lab Assistant & 1 \\
\hline
\end{tabular}

There are six Units in the Department of General Surgery which conduct the OP and Casualty on the six days of the week and on Sunday the Casualty is conducted by each Unit in turn. Thus the S 1 Unit conducts its OP on Mondays and S 6 Unit on Saturdays. Each Unit has a Major Surgical Day and a Minor Surgical Day in each week.

\begin{tabular}{|c|c|}
\hline \begin{tabular}{ll} 
& \multicolumn{1}{c}{ STRENGTHS } \\
- & Government institution serving a large \\
population from five northern districts of \\
Kerala \\
- $\quad$ Well qualified manpower \\
- $\quad$ Experienced senior staff \\
multi level discussions possible \\
regarding diagnosis, management \\
- $\quad$ Collective responsibility \\
- \\
- $\quad$ hervice of postgraduate surgeons \\
- & Salary in UGC patticient fund \\
- & Good infrastructure \\
- & Opportunities for collaborative research \\
- & Dollective research data \\
\end{tabular} & 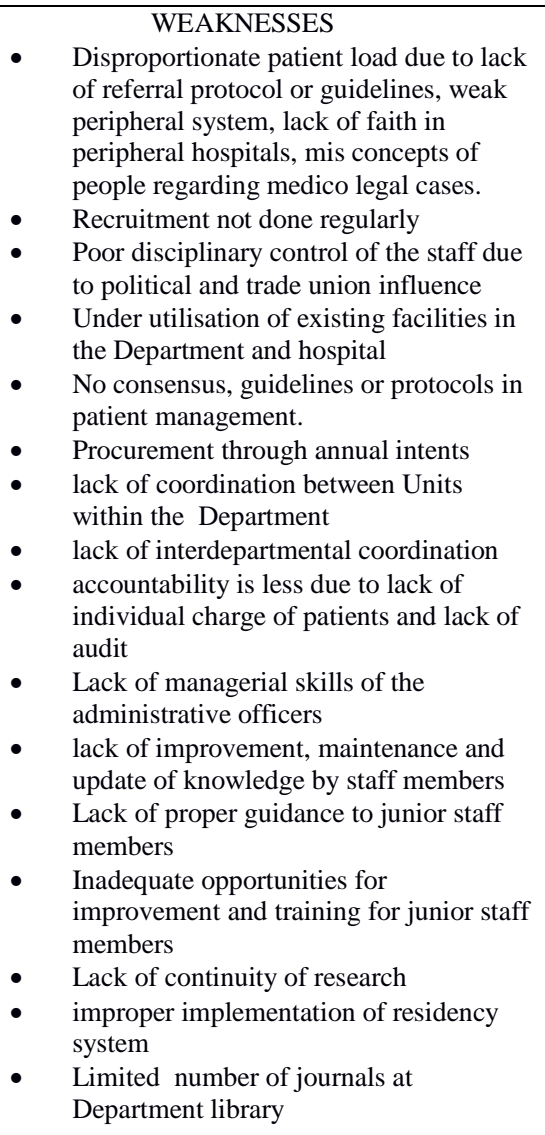 \\
\hline 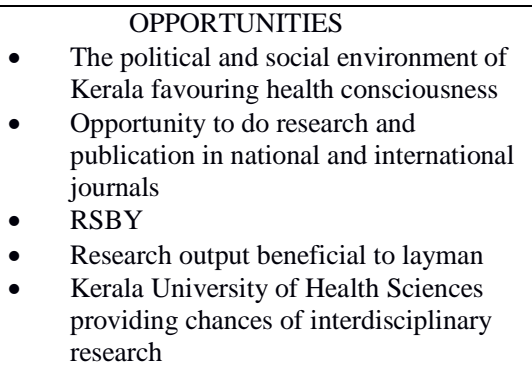 & \begin{tabular}{ll} 
& \multicolumn{1}{c}{ THREATS } \\
- & Brain drain to private hospitals \\
- & More focus on private practice \\
& Political changes in government changing \\
- $\quad$ Inappropriate Health Policy for the State
\end{tabular} \\
\hline
\end{tabular}

\section{Discussion}

SWOT Analysis is a tool that is used to identify the Strengths, Weaknesses, Opportunities and Threats of a System. It serves as a basic foundation for further improvements to the System using the findings. The strengths were used and weaknesses overcome. Opportunities can be explored and threats averted. The 
Government of Kerala and the Indian Medical Council govern the functioning of the Medical Colleges of the State. The teaching faculty of any Medical college should have a higher level of skills and efficiency for the delivery of high quality health care system and teaching medical students. The Department of General Surgery is a small department with 31 doctors and 2 auxiliary staff. So the strength, weaknesses, Opportunities and threats analysis was near complete. But similar analysis of other departments which closely associate with Department of General Surgery like the Departments of Anaesthesiology, Radiology, Transfusion Medicine, Anatomy, Pathology, Microbiology and Biochemistry is essential for effective implementation of the pro grammes and to improve the performance of the Department.

The pass percentage in university exams and the number of research publications in reputed indexed journals reflects the academic excellence of a department. Moreover a feedback from the students regarding their perception of the present teaching method provided useful information for a review in the present system of teaching ${ }^{1}$. Establishing a culture of respect and professionalism in today's teaching environment is one of the most important legacies that surgical educators can leave for the coming generation ${ }^{2}$. One major limitation of this study is that academic teaching reports were not analyzed.

Hospitals that operate at or over capacity may experience heightened rates of patient safety events ${ }^{3}$. To improve the safety and quality of care that patients receive from health professionals sustain the confidence to work effectively for different health care needs and approaches, and is able to adapt to future changes ${ }^{4}$. Evaluation measures the progress in achieving the goal by purposefully improving training programs and measuring their worth 5 .

Highly educated, trained and dedicated personals form the foundation of emergency services. Training Need Analysis programme leaded by Maria et al resulted in the design and delivery of a thriving continuing professional development programme for health care professionals ${ }^{6}$.

A survey conducted to improve the performance of the health care professionals at Saint Lucia, offered perspectives on how to conduct training need assessments planning and continuing professional education ${ }^{7}$. The major weaknesses like lack of coordination between Units, interdepartmental coordination should be minimized and acute care surgical system should be given priority. To improve patient care an acute care surgery system should be considered as procedure-related complications and unsatisfactory treatment results constitutes the major causes of medical disputes as reported by $\mathrm{Hu} \mathrm{YH}$ et al ${ }^{8}$. The conflicts at workplace, with perhaps the most devastating career consequences, are those that take place between employees and their superiors. Training an employee to get along well with authority and with people who entertain diverse points of view is one of the best guarantees of long term success ${ }^{9}$.

Health care system should have a strong Medical records filing and regular monitoring and supervision, so that it minimises issuance of incomplete data entry and misfiling. Health facilities must first assess the situation of the medical records by carrying out a situation analysis to obtain the direct and indirect factors leading to issuance of misfiling ${ }^{10}$.

\section{Conclusion}

From this study it is found that various problems and solutions to improve their performance through training and non-training interventions. There is a need for the Government to introduce creative incentives like career advancement promotion, higher training, cash incentives for research and flexible working environment.

\section{Acknowledgement}

The authors wish to express their heartfelt gratitude to the Head of the Department of General Surgery, Government Medical College Kozhikode for giving permission to conduct the study in the Department. The authors acknowledge Dr Sreejayan MP, Dr Muhammed Basheer OT and Dr Ajayakumar for their whole hearted cooperation and participation in the study.

\section{References}

[1]. Dr. Amar Jayanthi A, Dr. Sajna MMV and Benson Benjamin. Students perception of teaching learning method in dissection and histology lab. IOSR journal of dental and medical sciences. Nov 2014; Vol 13 (11): 24-28.

[2]. Connie C. Schmitz, Christopher j. Chow and David A. Rothenberger. Colorectal Surgeons Teaching General Surgery Residents: Current Challenges and Opportunities. Colon Rectal surg.. 2012 Sep; 25(3): 134-142.

[3]. Weissman JS, Rothschild JM, Bendavid E, Sprivulis P, Cook EF, Evans RS, Kaganova Y, Bender M, David-Kasdan J, Haug P, Lloyd J, Selbovitz LG, Murff HJ, Bates DW. Hospital workload and adverse events. Med Care. 2007 May; 45 (5): 448-55.

[4]. Fran Thorn. Credentialing and defining the scope of clinical practice for medical practitioners in Victorian health services - A policy handbook. Quality, Safety and Patient Experience Branch, Victorian Government, Department of Health, Melbourne, Victoria. 2011. p. 6.

[5]. Aarti chahal. A Study of Training Need Analysis Based Training and Development: Effect of Training on Performance by Adopting Development Based Strategy. International Journal of Business and Management Invention.2013; Volume 2 (4): 41-51.

[6]. Dr Mario R Sammut, MS Mariella Bombagi, MS Rebecca Cachia Fearne. A training needs analysis of health care providers within Malta's Primary Health Department - a boon or a bane?. The Journal of the Malta College of Family Doctors. August 2012; Volume 12(1): $13-17$. 
[7]. Janice Gaspard and Che-Ming Yang. Training needs assessment of health care professionals in a developing country: the example of Saint Lucia. BMC Medical Education. 2016; 16:112.

[8]. Hu YH, Wang CY, Huang MS, Lee CH, Wen YS. Analysis of the causes of surgery-related medical disputes in Taiwan: Need for acute care surgeons to improve quality of care. J Clin Med Assoc. 2016; 2016 Nov; 79(11):609-613.

[9]. Umesh U. A study of the importance of training and development of personnel of Cochin port trust, Kerala, India. Rev. Integr. Bus. Econ. Res. 2014; Vol 4 (1): 245 -252.

[10]. E. A A. Teviu1, m. aikins2, t. i . abdulai1, s. sackey2, p. boni3, e. afari2andf.wurapa2. improving medical records filing in a municipal hospital in Ghana. Ghana medical journal. Sept 2012; Vol 46 (3): 136 - 142. 